OPEN ACCESS

Edited by:

Linda L. Kusner,

George Washington University,

United States

Reviewed by:

Stefan Blum,

The University of Queensland,

Australia

Tomoki Suichi,

Chiba University Hospital, Japan

*Correspondence:

Soudeh Ghafouri-Fard

s.ghafourifard@sbmu.ac.ir

Specialty section:

This article was submitted to

Autoimmune and

Autoinflammatory Disorders,

a section of the journal

Frontiers in Immunology

Received: 21 May 2021 Accepted: 05 July 2021

Published: 19 July 2021

Citation:

Taheri M, Sangseifid S, Shahani P,

Eftekharian MM, Arsang-Jang S and Ghafouri-Fard S (2021)

Assessment of Expression of socs Genes in Acquired ImmuneMediated Polyneuropathies.

Front. Immunol. 12:712859. doi: 10.3389/fimmu.2021.712859

\section{Assessment of Expression of SOCS Genes in Acquired Immune- Mediated Polyneuropathies}

\author{
Mohammad Taheri $^{1}$, Somayeh Sangseifid ${ }^{2}$, Pariya Shahani ${ }^{3}$, \\ Mohammad Mahdi Eftekharian ${ }^{4}$, Shahram Arsang-Jang ${ }^{5}$ and Soudeh Ghafouri-Fard ${ }^{6 *}$ \\ 1 Skull Base Research Center, Loghman Hakim Hospital, Shahid Beheshti University of Medical Sciences, Tehran, Iran, \\ ${ }^{2}$ Department of Immunology, School of Medicine, Hamadan University of Medical Sciences, Hamadan, Iran, ${ }^{3}$ Department of \\ Cellular Molecular Biology, Faculty of New Sciences, Medical Tehran Branch, Islamic Azad University, Tehran, Iran, \\ ${ }^{4}$ Neurophysiology Research Center, Hamadan University of Medical Sciences, Hamadan, Iran, ${ }^{5}$ Cancer Gene Therapy \\ Research Center, Zanjan University of Medical Science, Zanjan, Iran, ${ }^{6}$ Department of Medical Genetics, School of Medicine, \\ Shahid Beheshti University of Medical Sciences, Tehran, Iran
}

Acquired immune-mediated polyneuropathies are classified to some subtypes among them are acute and chronic inflammatory demyelinating polyradiculoneuropathies (AIDP and CIDP). These two conditions share some common signs and underlying mechanisms. Based on the roles of Suppressor of cytokine signaling (SOCS) genes in the modulation of immune system reactions, these genes might be involved in the pathogenesis of these conditions. We evaluated expression of SOCS1-3 and SOCS5 genes in the leukocytes of 32 cases of CIDP, 19 cases of AIDP and 40 age- and sexmatched controls using real time PCR method. The Bayesian regression model was used to estimate differences in mean values of genes expressions between cases and control group. Expression levels of SOCS1 and SOCS2 were significantly lower in male patients compared with controls. This sex-specific pattern was also observed for SOCS3 downregulation. Based on the area under curve values in Receiver Operating Characteristics (ROC) curve, diagnostic powers of SOCS1, SOCS2, SOCS3 and SOCS5 genes in the mentioned disorder were $0.61,0.73,0.68$ and 0.58 , respectively. Expression of none of genes was correlated with age of enrolled cases. The current study shows evidences for participation of SOCS genes in the pathophysiology of acquired immunemediated polyneuropathies.

Keywords: acquired immune-mediated polyneuropathies, Guillain-Barré syndrome, CIDP, AIDP, suppressor of cytokine signaling

\section{INTRODUCTION}

Immune-mediated neuropathies embrace a variety of peripheral nerve disorders which can be classified according to the course of signs evolution, principal engagement of motor/sensory fibers, dispersal of signs and paraclinical factors $(1,2)$. Two types of these neuropathies are Guillain-Barré syndrome (GBS) and chronic inflammatory demyelinating polyradiculoneuropathy (CIDP) (2). GBS can be classified to acute IDP (AIDP) and axonal forms with variable incidences in different 
parts of the world (2). AIDP accounts for more than $90 \%$ of GBS patients in Western world (3). The pathologic events during evolution of GBS are commonly triggered by environmental factors such as infections or vaccination that stimulate abnormal immune responses, interruption in the blood-nerve barrier and demolition of myelin sheaths and/or axons (4-6). Aberrant immune responses in GBS are mostly mediated by $\mathrm{T}$ helper cell-dependent induction of macrophages (7). While several studies have highlighted the role of Th1 cells producing proinflammatory cytokines in this condition, some pathogenic events in the GBS cannot be explained by Th1/Th2 imbalance, so other types of T cells such as Th17 and regulatory T cells might also been involved in this process (8).

CIDP is another type of immune mediated neuropathies which is described by the involvement of proximal and distal motor/sensory fibers. This disorder can have relapsing or progressive courses (9). Several parts of immune regulatory mechanisms including antibodies against autoantigens, complement, $\mathrm{T}$ lymphocytes and macrophage cells are involved in triggering abnormal immune response in CIDP (9).

Suppressors of cytokine signaling (SOCS) proteins represent a family of proteins which are located inside the cell and partake in the regulation of immune cell responses to cytokines (10). As negative regulators of the cytokine-JAK-STAT pathway, these proteins participate in diverse immune-related and pathological processes (10). Aberrant expressions of SOCS proteins have been linked with some immunological diseases such as rheumatoid arthritis (11), inflammatory bowel disease (12), allergic responses (13) and multiple sclerosis (14).

Since SOCS proteins partake in the control of immune cascades, we evaluated expression of SOCS1-3 and SOCS5 genes in the peripheral blood cells of individual affected by immunemediated neuropathies and healthy controls to find their possible role in the pathophysiology of this immune-related condition. The reason for selection of SOCS1-3 and SOCS5 genes was their aberrant expression in bipolar disorder, a neurological disorder in which aberrant immune responses are involved in the pathogenesis (15). We also aimed at assessment of their possible application as biomarkers for this disorder. This field has been explored by a number of recent studies that focused on identification of differentially expressed molecules between GBS patients and healthy subjects. These novel biomarkers can be applied for identification of the pathophysiology of this disorder, primary diagnosis, intervention, and judgment about the prognosis (16).

\section{MATERIALS AND METHODS}

\section{Patients and Normal Subjects}

The current investigation was conducted on blood samples obtained from 32 cases of typical CIDP (10 females and 22 males), 19 cases of AIDP (6 females and 13 males) and 40 healthy subjects (11 females and 29 males) (Table 1). Patients were recruited during April 2019-April 2020 from Imam Hossein hospital, Tehran, Iran. AIDP and CIDP patients were diagnosed
TABLE 1 | Demographic data of enrolled people in the study.

\begin{tabular}{lcc}
\hline Variables & Patients & $\begin{array}{c}\text { Healthy } \\
\text { subjects }\end{array}$ \\
\hline Female/Male [no. (\%)] & $16(32 \%) / 35$ & $11(27.5 \%) / 29$ \\
& $(68 \%)$ & $(72.5 \%)$ \\
Age (mean \pm standard deviation, Y) & $36.2 \pm 2.7$ & $35.3 \pm 2.4$ \\
Age range (Y) & $18-85$ & $19-81$ \\
Age of onset (mean \pm standard deviation, Y) & $31.42 \pm 2.79$ & - \\
Disease duration (mean \pm standard deviation, Y) & $4.57 \pm 3.19$ & - \\
\hline
\end{tabular}

based on guidelines described by European Federation of Neurological Societies (17) and National Institute of Neurological Disorders and Stroke (18). Besides, electrophysiological criteria were used for diagnosis of AIDP cases (19). Patients had no obvious sign or symptom of disorder at the time of blood sampling and did not take any immune modulatory drug in at least 2 weeks prior to sampling (20). All of AIDP and CIDP cases were in remission. None of study participants had recent or chronic infection, neoplasm or any systemic disorder which alters immune responses. The study protocol was approved by ethical committee of Shahid Beheshti University of Medical Sciences (IR.SBMU.MSP.REC.1398.855). All study participants signed the informed consent forms.

\section{Expression Assays}

Peripheral blood samples were gathered from patients and controls in EDTA-containing tubes. Total RNA was extracted from blood samples using the commercial kit provided by GeneAll Company after red blood cells lysis (Seoul, South Korea). Next, cDNA was produced from 50-100 ng of RNA (BioFact ${ }^{\mathrm{TM}}$, Seoul, South Korea). The RealQ Plus 2x Master Mix for Probe (Ampliqon) and StepOnePlus ${ }^{\mathrm{TM}}$ RealTime PCR System (Applied Biosystems, Foster city, CA, USA) were used for real time PCR. Table 2 shows the features of primers and probes. PCR program comprised an initial activation phase for 5 minutes at $94^{\circ} \mathrm{C}$, and 40 cycles at $94^{\circ} \mathrm{C}$ for 10 seconds and $60{ }^{\circ} \mathrm{C}$ for 40 seconds. Total reaction volumes were $20 \mu \mathrm{L}$ containing 4 $\mu \mathrm{l}$ of cDNA, $3.5 \mu \mathrm{l}$ double distilled water, $10 \mu \mathrm{l}$ of Master Mix $2 \times$, $250 \mathrm{nM}$ and $900 \mathrm{nM}$ concentrations of probe and each primer, respectively. Cycle threshold $(\mathrm{Ct})$ values of genes were corrected for efficiency of amplification. Relative expression of genes in each sample was estimated based on calculation of $\mathrm{Ln}$ [Efficiency^$\triangle \mathrm{CT}$ ] values. Efficiency values for SOCS genes and HPRT1 were between 1.7 and 1.9.

\section{Statistical Methods}

The Bayesian regression model using Laplace prior family was used to estimate differences in genes expressions between cases and control group. This method permitted control of the effects of gender, age, and assessment of group ${ }^{\star}$ gender interaction effects. Models compared using Watanabe-Akaike information criterion and leave-one-out cross-validation. The Receiver Operating Characteristic (ROC) regression model was used to estimate best cut-off values of expression levels of genes for distinguishing cases from controls. The figures of the Bayesian model were appraised using Hamiltonian Monte Carlo chains 
TABLE 2 | The detailed features of primers.

\begin{tabular}{|c|c|c|}
\hline Gene name & Primer and probe sequence & $\begin{array}{l}\text { Product } \\
\text { size }\end{array}$ \\
\hline HPRT1 & $\begin{array}{l}\text { F: AGCCTAAGATGAGAGTTC } \\
\text { R: CACAGAACTAGAACATTGATA } \\
\text { FAM -CATCTGGAGTCCTATTGACATCGC- } \\
\text { TAMRA }\end{array}$ & 88 \\
\hline SOCS1 & $\begin{array}{l}\text { F: TGGCCCCTTCTGTAGGATGG } \\
\text { R: GGAGGAGGAAGAGGAGGAAGG } \\
\text { FAM- TGGCCCCTTCTGTAGGATGG- TAMRA }\end{array}$ & 109 \\
\hline socs2 & $\begin{array}{l}\text { F: ACGCGAACCCTTCTCTGACC } \\
\text { R: CATTCCCGGAGGGCTCAAGG } \\
\text { FAM -CTCGGGCGGCCACCTGTCTITGC-TAMRA }\end{array}$ & 99 \\
\hline sOCS3 & $\begin{array}{l}\text { F: GTGGAGAGGCTGAGGGACTC } \\
\text { R: GGCTGACATTCCCAGTGCTC } \\
\text { FAM- CACCAAGCCAGCCCACAGCCAGG- } \\
\text { TAMRA }\end{array}$ & 111 \\
\hline SOCS5 & $\begin{array}{l}\text { F: GTGACTCGGAAGAGGATACAACC } \\
\text { R: CTAACATGGGTATGGCTGTCTCC } \\
\text { FAM- CGCTGCTTCTGCCTCCGTGACTGC- } \\
\text { TAMRA }\end{array}$ & 91 \\
\hline
\end{tabular}

with 6000 iterations and 1000 warm-up in RStan C++ library. The optimal cut-off values in ROC curve analysis were determined using the Youden index (J) method. The pROC, Stan, loo, and shynistan packages were used in R 3.6.1 software. The Hybrid Monte Carlo algorithm was used to yield more efficient estimates through the posterior distribution. The model convergence was checked by R-hat and Gelman-Rubin diagnostics available in Shynistan. $\mathrm{P}$ values and 95\% credible interval (95\% CrI) were calculated. P values were computed from the quantile regression model using the bootstrap method.

\section{RESULTS}

\section{Information About Study Participants}

The study included 32 cases of CIDP and 19 cases of AIDP. Demographic data of these individuals are summarized in Table 2.

\section{Expression Assays}

Expression levels of SOCS1 and SOCS2 were significantly lower in patients compared with controls (Posterior Beta $=-2.18$, $\mathrm{P}=0.029$; Posterior Beta $=-3.19, \mathrm{P}<0.0001$, respectively). When assessing expression levels of these genes in distinct sex-based subgroups, differences in their expressions were significant in male subgroups but not female subgroups. Expression of SOCS3 was significantly lower in male patients compared with male controls (Posterior Beta $=-3.44, \mathrm{P}=0.037$ ). However, expression of this gene was not different between female subclasses (Posterior Beta $=-0.87, \mathrm{P}=0.528$ ). Expression of SOCS5 was not different between cases and controls or between sex-based subgroups of them. Figure $\mathbf{1}$ and Table $\mathbf{3}$ show the details of assessment of expression of SOCS genes between cases and control subjects. There was no remarkable difference in expression of any SOCS gene between AIDP and CIDP patients.
Subsequently, we assessed differences in the expression of SOCS genes in AIPD cases versus CIDP cases (Table 4). Expression of SOCS1 was significantly higher in AIDP cases compared with CIDP cases. When assessing gene expression in sex-based subgroups, differences were significant only in male subgroups. Expressions of other SOCS were not different between AIPD and CIDP cases.

Additionally, expression of SOCS genes was compared between AIDP cases and controls (Table 5). Expression of SOCS1 was higher in AIDP cases versus controls (Posterior beta $=4.779$, P value $<0.0001)$. Similarly, expressions of SOCS2 and SOCS3 were higher in AIDP cases compared with controls (Posterior beta $=3.765, \mathrm{P}$ value $=0.005$ and Posterior beta $=2.757, \mathrm{P}$ value $=0.036$, respectively). However, expression of SOCS5 was not different between AIDP cases and controls.

\section{ROC Curves}

Based on the AUC values, diagnostic powers of SOCS genes in the mentioned disorder were $0.61,0.73,0.68$ and 0.58 , respectively.

Figure 2 shows the results of ROC curves assessments.

There were significant differences in diagnostic power of SOCS2 and SOCS3 genes $(\mathrm{P}=0.04)$ and SOCS2 and SOCS5 $(\mathrm{P}=0.018)$ (Figure 3).

Then, we combined ROC curves of pairs of SOCS genes and SOCS1-3 genes together (Figure 4). Combination of SOCS1 and SOCS 2 genes provided the best AUC value (AUC $=0.775$, sensitivity $=62.75 \%$, Specificity $=87.5 \%$ ).

\section{Correlation Analysis}

Remarkable correlations were demonstrated between expressions of SOCS 2 and SOCS3 $(\mathrm{r}=0.55, \mathrm{P}<0.0001)$, SOCS 2 and SOCS5 $(\mathrm{r}=0.48, \mathrm{P}<0.0001)$, and SOCS5 and SOCS3 $(\mathrm{r}=0.52$, $\mathrm{P}<0.0001)$. Expression levels of SOCS genes were not correlated with age of either patients or healthy subjects.

\section{DISCUSSION}

We examined expression of SOCS genes in the samples of peripheral blood cells obtained from AIDP and CIDP patients versus healthy individuals. These two autoimmune conditions have common clinical symptoms, histologic signs and similar therapeutic options (immunosuppressive therapy) (21). The role of aberrant immune responses in these types of neuropathies has been vastly investigated. Among the well-appreciated underlying mechanisms are activation of cellular adhesion molecules that permit transmission of autoreactive T cells and B cells across the bloodnerve barrier, activation of macrophages and enhancement of their phagocytic activity by $\mathrm{T}$ lymphocytes, secretion of inflammatory cytokines, nitric oxide, reactive oxygen species and proteases $(5,22)$. SOCS proteins partake in the regulation of many aspects of immune responses through inhibiting the Jak/STAT signaling pathway (23). Jak-STAT pathway is active in some immune cells including macrophages at a basal level and is robustly activated during innate responses (24). Based on the prominent pathogenic role of macrophages in the immune-related neuropathies, 
A

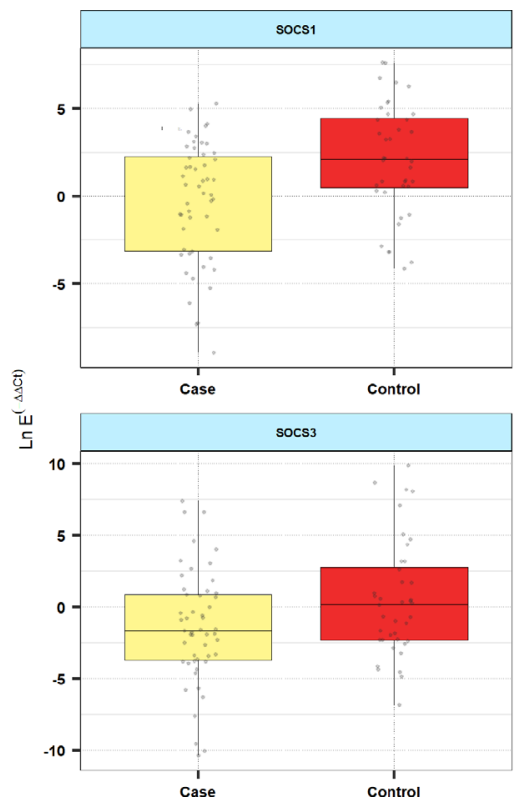

B

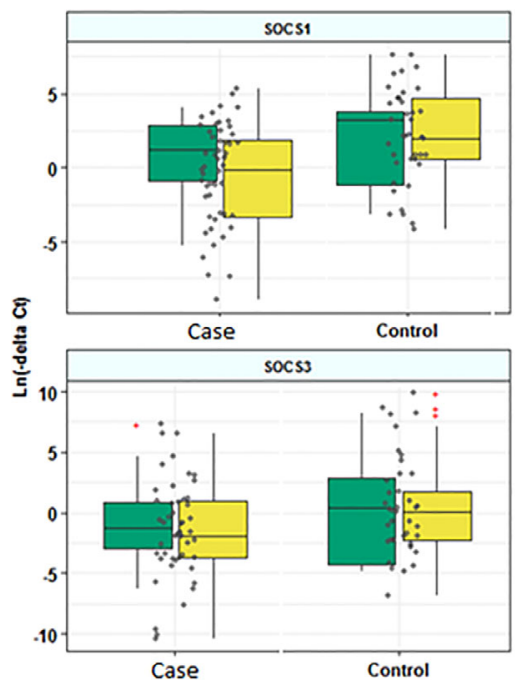

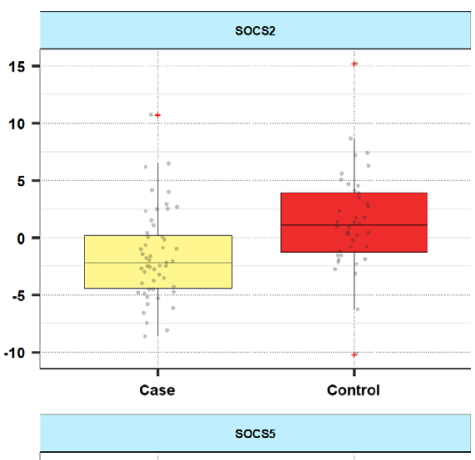

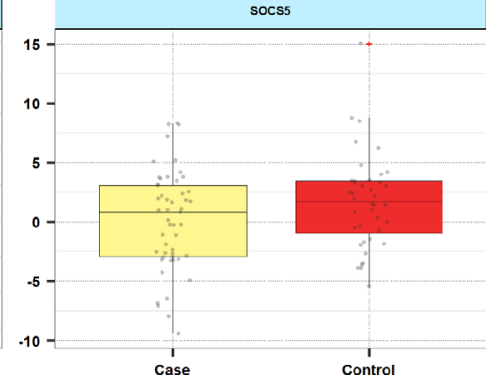

Case

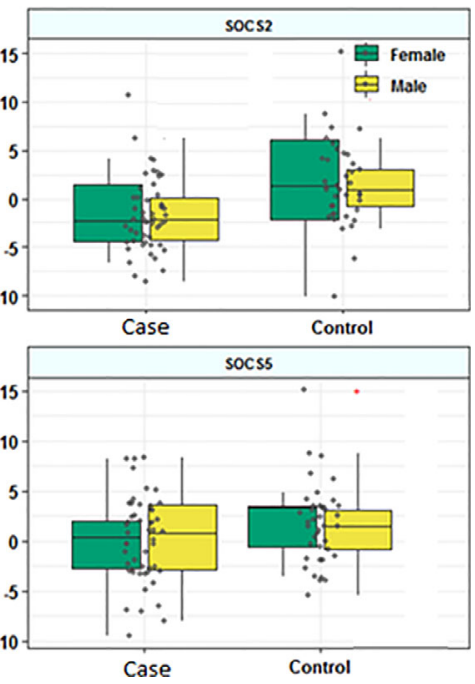

FIGURE 1 | Relative expression of SOCS genes in patients and controls (A) and based on the gender of study participants (B).

SOCS proteins are possible molecules that could modulate aberrant immune responses in the immune-related neuropathies. However, it is worth mentioning that SOCS proteins are not specifically expressed by macrophages. Therefore, their expression would not necessarily reflect macrophage activation. Moreover, SOCS proteins might have specific functions. For instance, SOCS1 has a role in the development of acute/chronic myeloid leukemia, glioblastoma and Barrett's adenocarcinoma. SOCS2 partake in the pathogenesis of ovarian cancer, acromegaly associated colonic polyps, osteoarthritis and type 2 diabetes. SOCS3 is involved in the pathobiology of prostate cancer, ulcerative colitis, breast cancer and atopic asthma/ dermatitis. Finally, SOCS5 contribute in the pathogenesis of uveitis and thyroid cancer (25). We detected lower expressions of SOCS1 and SOCS2 in patients compared with healthy subjects. SOCS1 has been shown to be implicated in the pathogenesis of some immunerelated disorders. Lack of Socs1 in a murine model of autoimmune arthritis has led to considerable increase in joint inflammation and destruction (26). Moreover, down-regulation of SOCS1 expression has a role in guiding the pro-inflammatory $\mathrm{M} 1$ role of macrophages by activating the JAK/STAT pathway (27). Sosc2 has been shown to improve recovery process of traumatic brain injury in mice through modulation of neuroinflammatory response and stimulation of a more anti-inflammatory setting through alerting M1/M2 macrophages ratio (28). Thus, the observed down-regulation of 
TABLE 3 | Relative expression of SOCS genes in patients and controls.

\begin{tabular}{|c|c|c|c|c|c|c|c|c|c|c|c|c|c|c|c|c|c|}
\hline & \multirow[t]{2}{*}{ Variable } & \multicolumn{4}{|c|}{ socs1 } & \multicolumn{4}{|c|}{ socs2 } & \multicolumn{4}{|c|}{ socs3 } & \multicolumn{4}{|c|}{ socs5 } \\
\hline & & $\begin{array}{c}\text { Posterior } \\
\text { Beta }\end{array}$ & SE & $\begin{array}{c}\mathrm{P}- \\
\text { value }\end{array}$ & $95 \% \mathrm{Crl}$ & $\begin{array}{l}\text { Posterior } \\
\text { Beta }\end{array}$ & SE & P-value & $95 \% \mathrm{Crl}$ & $\begin{array}{l}\text { Posterior } \\
\text { Beta }\end{array}$ & SE & $\begin{array}{c}\mathrm{P}- \\
\text { value }\end{array}$ & $95 \% \mathrm{Crl}$ & $\begin{array}{l}\text { Posterior } \\
\text { Beta }\end{array}$ & SE & $\begin{array}{l}\mathrm{P}- \\
\text { value }\end{array}$ & $95 \% \mathrm{Crl}$ \\
\hline \multirow[t]{4}{*}{ Total } & $\begin{array}{l}\text { Group } \\
\text { (Case/Control) }\end{array}$ & -2.18 & 0.78 & 0.029 & {$[-3.71,-0.7]$} & -3.19 & 0.79 & $<0.0001$ & {$[-4.76,-1.65]$} & -1.35 & 0.76 & 0.061 & {$[-2.85,0.16]$} & -1.33 & 0.79 & 0.692 & {$[-2.85,0.25]$} \\
\hline & Gender & -0.92 & 0.74 & 0.18 & {$[-2.34,0.57]$} & 0.16 & 0.9 & 0.934 & {$[-1.69,1.94]$} & 0.05 & 0.95 & 0.711 & {$[-1.85,1.96]$} & -0.04 & 0.9 & 0.454 & {$[-1.8,1.81]$} \\
\hline & Age & -0.01 & 0.02 & 0.855 & {$[-0.06,0.04]$} & 0.01 & 0.02 & 0.409 & {$[-0.03,0.04]$} & 0.02 & 0.02 & 0.335 & {$[-0.02,0.07]$} & 0.04 & 0.03 & 0.015 & {$[-0.01,0.09]$} \\
\hline & Group*Gender & -0.98 & 1.49 & 0.826 & {$[-3.74,2.18]$} & -1 & 2.06 & 0.986 & {$[-5.15,2.89]$} & -1.14 & 2.24 & 0.504 & {$[-5.28,3.24]$} & 2.17 & 1.67 & 0.443 & {$[-1.01,5.59]$} \\
\hline \multirow[t]{2}{*}{ Male } & $\begin{array}{l}\text { Group } \\
\text { (Case/Control) }\end{array}$ & -2.46 & 0.96 & 0.047 & {$[-4.27,-0.51]$} & -3.44 & 0.84 & $<0.0001$ & {$[-5.19,-1.82]$} & -3.44 & 0.84 & 0.037 & {$[-5.19,-1.82]$} & -0.75 & 1.07 & 0.684 & {$[-2.8,1.36]$} \\
\hline & Age & -0.01 & 0.03 & 0.872 & {$[-0.06,0.04]$} & 0.01 & 0.02 & 0.449 & {$[-0.03,0.05]$} & 0.01 & 0.02 & 0.723 & {$[-0.03,0.05]$} & 0.05 & 0.04 & 0.233 & {$[-0.03,0.11]$} \\
\hline \multirow[t]{2}{*}{ Female } & $\begin{array}{l}\text { Group } \\
\text { (Case/Control) }\end{array}$ & -1.69 & 1.34 & 0.229 & {$[-4.37,0.79]$} & -1.69 & 1.34 & 0.389 & {$[-4.37,0.79]$} & -0.87 & 1.99 & 0.528 & {$[-4.98,2.77]$} & -2.26 & 1.31 & 0.062 & {$[-5.23,0.01]$} \\
\hline & Age & -0.02 & 0.04 & 0.583 & {$[-0.1,0.06]$} & -0.02 & 0.04 & 0.783 & {$[-0.1,0.06]$} & 0.04 & 0.05 & 0.432 & {$[-0.06,0.14]$} & 0.02 & 0.04 & 0.681 & {$[-0.06,0.1]$} \\
\hline
\end{tabular}

TABLE 4 | Relative expression of SOCS genes in AIPD cases versus CIDP cases.

\begin{tabular}{|c|c|c|c|c|c|c|c|c|c|c|c|c|c|c|c|c|}
\hline \multirow[t]{2}{*}{ Group } & \multicolumn{4}{|c|}{ socs1 } & \multicolumn{4}{|c|}{ socs2 } & \multicolumn{4}{|c|}{ socs3 } & \multicolumn{4}{|c|}{ socs5 } \\
\hline & Posterior Beta & SE & P-value & $95 \% \mathrm{Crl}$ & Posterior Beta & SE & P-value & $95 \% \mathrm{Crl}$ & Posterior Beta & SE & P-value & $95 \% \mathrm{Crl}$ & Posterior Beta & SE & P-value & $95 \% \mathrm{Crl}$ \\
\hline Total & 3.816 & 0.88 & 0.001 & {$[1.98,5.45]$} & 0.809 & 1.06 & 0.419 & {$[-1.21,2.97]$} & 2.009 & 1.23 & 0.442 & {$[-0.23,4.76]$} & 0.013 & 1.16 & 0.684 & {$[-2.25,2.34]$} \\
\hline Male & 4.266 & 0.92 & $<0.0001$ & {$[2.48,6.05]$} & 0.458 & 1.31 & 0.413 & {$[-2,3.13]$} & 5.023 & 1.76 & 0.046 & {$[1.17,7.83]$} & -0.089 & 1.58 & 0.721 & {$[-3.05,3.15]$} \\
\hline Female & 2.51 & 2.03 & 0.13 & {$[-1.34,6.65]$} & 4.461 & 3.13 & 0.63 & {$[-2.15,10.29]$} & 1.464 & 2.82 & 0.4 & {$[-3.89,6.77]$} & 2.279 & 1.59 & 0.655 & {$[-1.07,5.54]$} \\
\hline
\end{tabular}

TABLE 5 | Relative expression of SOCS genes in AIDP cases versus controls.

\begin{tabular}{|c|c|c|c|c|c|c|c|c|c|c|c|c|c|c|c|c|}
\hline \multirow[t]{2}{*}{ Group } & \multicolumn{4}{|c|}{ socs1 } & \multicolumn{4}{|c|}{ socs2 } & \multicolumn{4}{|c|}{ socs3 } & \multicolumn{4}{|c|}{ socs5 } \\
\hline & Posterior Beta & SE & P-value & $95 \% \mathrm{Crl}$ & Posterior Beta & SE & P-value & $95 \% \mathrm{Crl}$ & Posterior Beta & SE & P-value & $95 \% \mathrm{Crl}$ & Posterior Beta & SE & P-value & $95 \% \mathrm{Crl}$ \\
\hline Total & 4.779 & 0.87 & $<0.0001$ & {$[3.05,6.45]$} & 3.765 & 1.1 & 0.005 & {$[1.62,6.04]$} & 2.757 & 1.2 & 0.036 & {$[0.58,5.43]$} & 1.359 & 1.03 & 0.655 & {$[-0.62,3.45]$} \\
\hline Male & 5.178 & 0.98 & $<0.0001$ & {$[3.33,7.25]$} & 3.855 & 1.24 & $<0.0001$ & {$[1.39,6.31]$} & 5.917 & 1.73 & 0.032 & {$[2.05,8.51]$} & 0.723 & 1.48 & 0.866 & {$[-2.03,3.84]$} \\
\hline Female & -0.007 & 0.05 & 0.168 & {$[-0.1,0.09]$} & 0.002 & 0.07 & 0.332 & {$[-0.14,0.14]$} & 0.054 & 0.06 & 0.451 & {$[-0.06,0.18]$} & 0.022 & 0.04 & 0.295 & {$[-0.07,0.11]$} \\
\hline
\end{tabular}




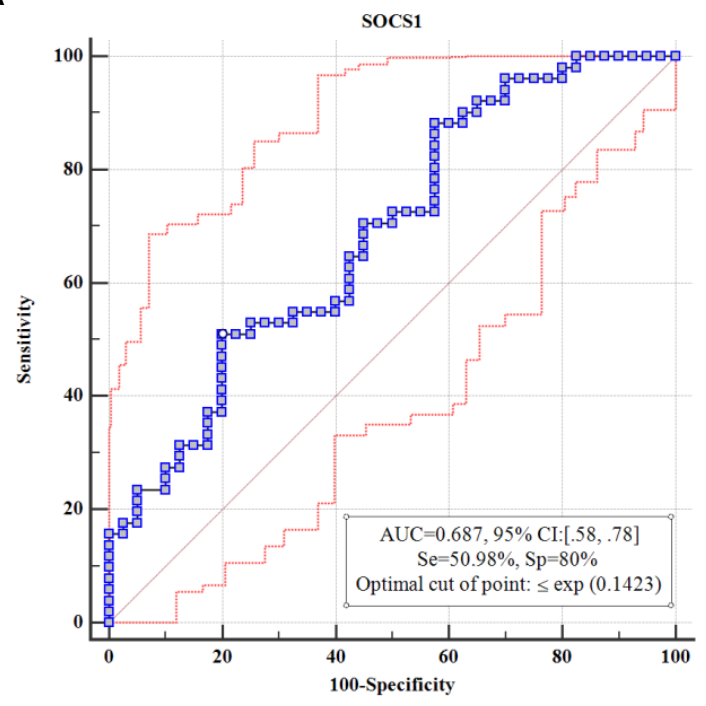

C

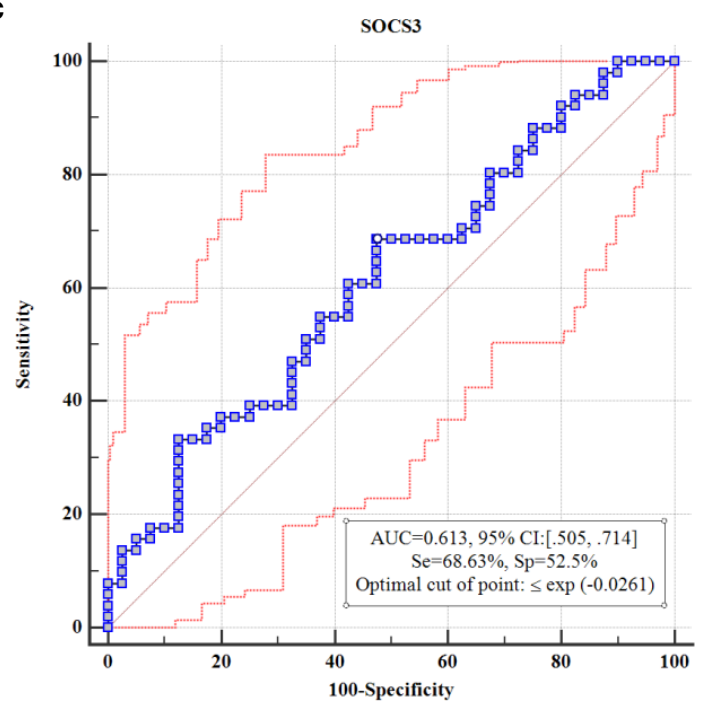

B

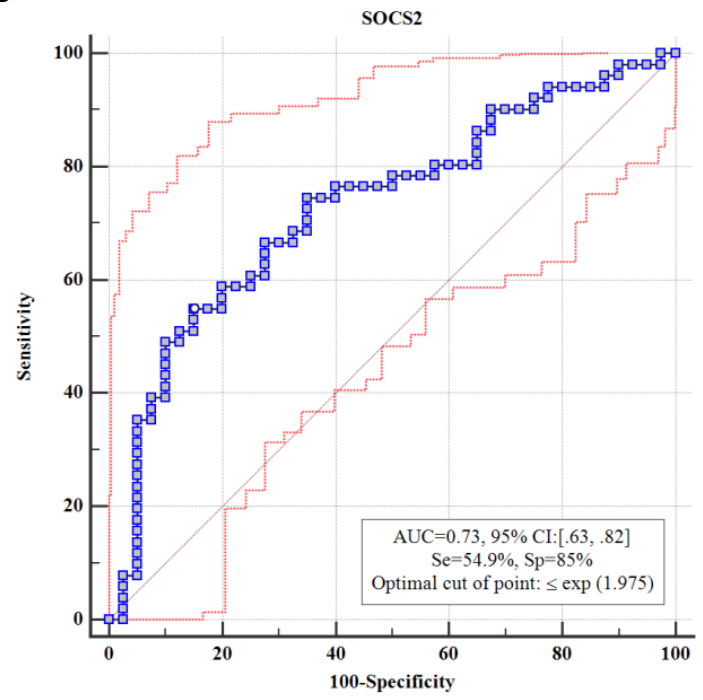

D

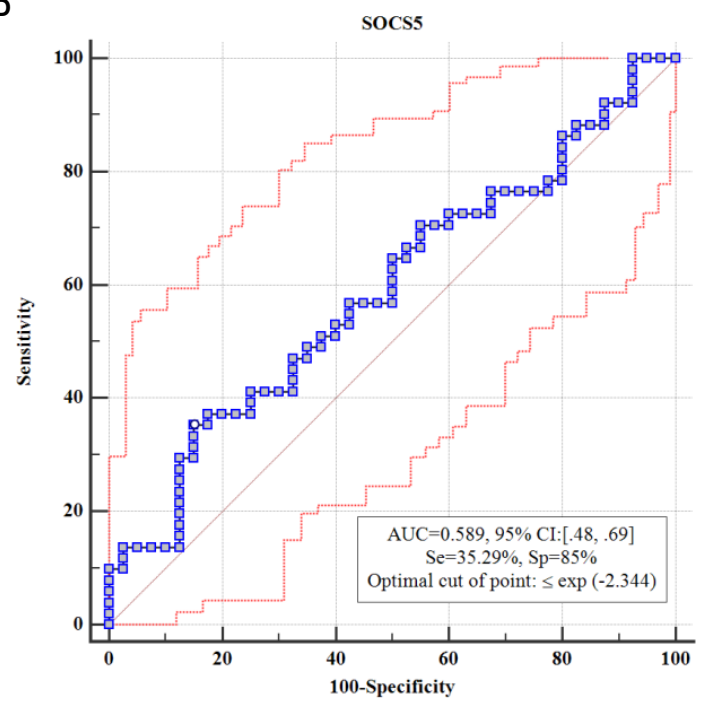

FIGURE 2 | Results of ROC curve analysis for SOCS1 (A), SOCS2 (B), SOCS3 (C) and SOCS5 (D), respectively.

SOCS2 in patients with immune-related neuropathies is in line with the role of M1 proinflammatory macrophages in GBS pathogenesis.

When assessing expression levels of these genes in distinct sex-based subgroups, differences in their expressions were significant in male subgroups but not female subgroups. Although studies regarding the role of sex hormones of expression of SOCS genes are few, a previous study has shown activation of SOCS2 expression by estradiol (29). Thus, lack of difference in expression of SOCS2 between female patients and female controls might be at least partially explained by the regulatory effects of estradiol on its expression. Alternatively, as the sample size of females is considerably smaller than males, the significant finding in males (but not females) might be explained by the differences in the sample sizes. In other words, there might be not really enough age-matched cases/ controls to segregate subjects by their sex, i.e. there were not enough female cases to provide meaningful comparison.

In addition, we compared expression of SOCS genes between AIDP cases and CIDP cases and detected higher expression of SOCS1 in male AIDP cases compared with male CIDP cases. Yet, based on the small sample size in this subgroup analysis, the power of this analysis is limited. Thus, we propose conduction of further similar studies in larger sample sizes to find whether the functional role of SOCS genes/proteins is different in CIDP and AIDP.

Expression of SOCS3 was significantly lower in male patients compared with male controls. However, expression of this gene was not different between female subgroups. SOCS3 has a selective role in inhibition of IL-6 signaling, restricting its 


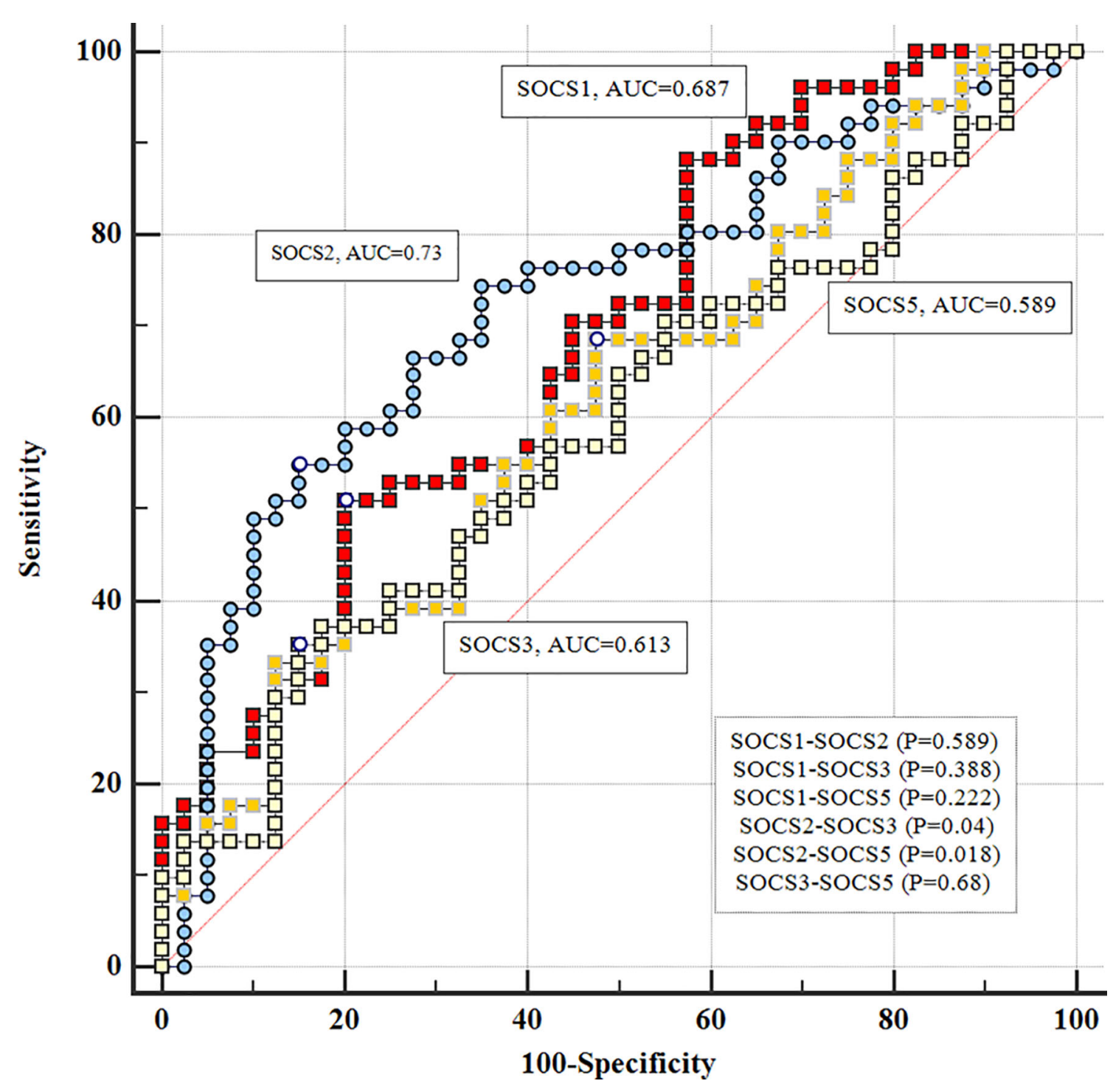

FIGURE 3 | Comparison of diagnostic power of SOCS genes in patients.

ability to inhibit LPS signaling (10). Lack of Socs3 gene in macrophages and neutrophils has increased Th1 activity and secretion of inflammatory cytokines including TNF- $\alpha$, IL- 1 , IFN- $\boldsymbol{\gamma}$ and IL-6 (30). Consequently, our observation regarding lower levels of SOCS3 in patients is in harmony with the detected phenotype in Socs3-devoid mice. Lack of difference in expression of this gene between female subgroups is best explained by the small sample size of this subgroup.

We also assessed the diagnostic power of these genes. Based on the area under curve values in ROC curve, diagnostic powers of SOCS1, SOCS2, SOCS3 and SOCS5 genes in immune-related neuropathies were $0.61,0.73,0.68$ and 0.58 , respectively. Although none of them is regarded as sensitive or specific biomarker of this disorder, they might be incorporated in putative diagnostic panels for this immune-related condition to predict immune status of patients. However, this speculation should be appraised in future investigations. Combination of SOCS1 and SOCS2 genes has enhanced the diagnostic power and yielded the AUC value of 0.775 . Previous studies have reported diagnostic value of a number of molecules in GBS. For instance, Li et al. have demonstrated up-regulation of haptoglobin and heat shock protein 70, while down-regulation of cystatin $\mathrm{C}$ in cerebrospinal fluid (CSF) of GBS patients. Their results indicated the biomarker roles for these proteins for early GBS diagnosis, though these proteins could not differentiate AIDP and acute motor axonal neuropathy (16). Other studies have suggested a number of infection-/immune-/blood-nerve barrier and the blood-CSF barrier, and peripheral nervous system damage-related biomarkers. However, the clinical applications of several of these suggested biomarkers have been limited by the 
A

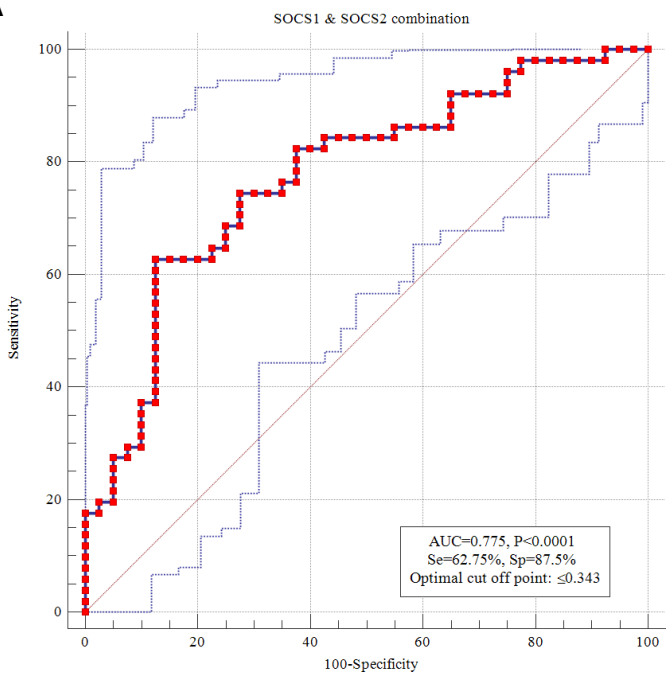

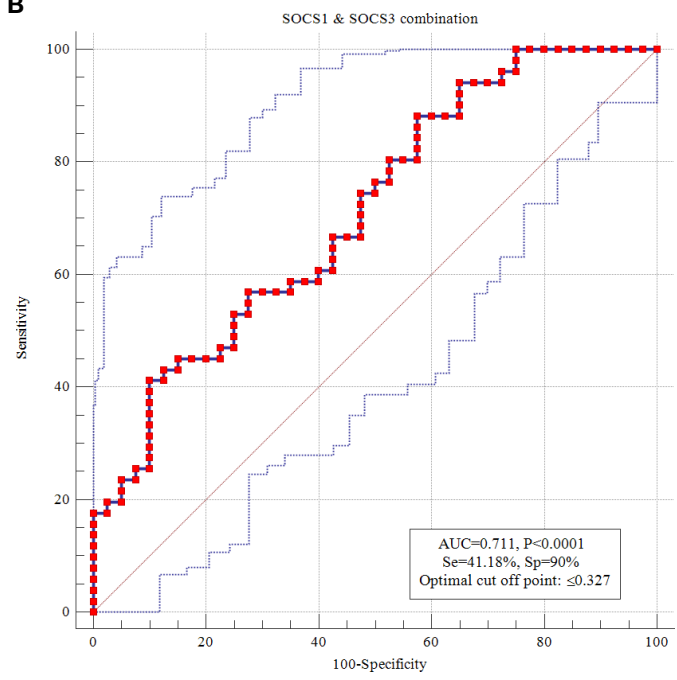

C

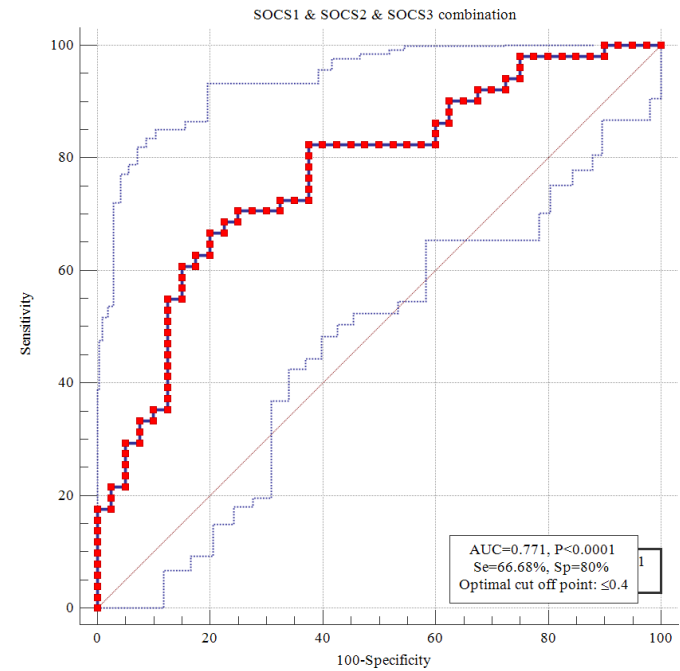

FIGURE 4 | ROC curves using combination of transcript amounts of SOCS1 and SOCS2 (A), SOCS1 and SOCS3 (B) and SOCS1-3 (C).

expense of the discovery method, invasiveness of the needed procedure and low sensitivity/specificity (31). Based on the results of ROC curves, individual SOCS genes do not differentiate well between patients and controls. However, combination of these genes might result in better values. Thus, further studies are needed to suggest more sensitive biomarkers for this disorder.

Significant correlations were detected between expressions of SOCS2 and SOCS3, SOCS2 and SOCS5, and SOCS5 and SOCS3. Previous studies have shown the role of SOCS2 in regulation of the protein levels of SOCS1 and SOCS3 $(32,33)$. SOCS2 has specifically increased SOCS3 degradation (33). However, the observed direction of correlation between these two SOCS members in the current study is not in accordance with this regulatory effect. Consequently, our observation indicates a more complicated interactive network between SOCS genes which should be identified in future studies.
Expression of none of genes was correlated with age of enrolled persons. This finding is in agreement with the results of our recent study of SOCS genes expressions in breast cancer patients which revealed independence of expression of these genes from age (34).

Taken together, the current study provides evidences for participation of SOCS genes in the pathophysiology of CIDP/ GBS and necessitates conduction of future functional studies to clarify the underlying mechanism. However, as RNA abundance does not necessarily correlate with protein abundance, we state lack of assessment of SOCS proteins as a limitation of our study. Thus, for translation of the results of study in clinical application, it is necessary to address this point. Besides, we state lack of assessment of genes expression at the active phase of disorder as another limitation of our study. Further studies are needed to test whether these conclusions are valid. 


\section{DATA AVAILABILITY STATEMENT}

The original contributions presented in the study are included in the article/supplementary material. Further inquiries can be directed to the corresponding author.

\section{ETHICS STATEMENT}

The study protocol was approved by ethical committee of Shahid Beheshti University of Medical Sciences (IR.SBMU.MSP.REC. 1398.855). The patients/participants provided their written informed consent to participate in this study.

\section{REFERENCES}

1. Safa A, Azimi T, Sayad A, Taheri M, Ghafouri-Fard S. A Review of the Role of Genetic Factors in Guillain-Barré Syndrome. J Mol Neurosci: MN (2020) 7:19. doi: 10.1007/s12031-020-01720-7

2. Lehmann HC, Meyer Zu Horste G, Kieseier BC, Hartung HP. Pathogenesis and Treatment of Immune-Mediated Neuropathies. Ther Adv Neurol Disord (2009) 2(4):261-81. doi: 10.1177/1756285609104792

3. Hadden RD, Cornblath DR, Hughes RA, Zielasek J, Hartung HP, Toyka KV, et al. Electrophysiological Classification of Guillain-Barre Syndrome: Clinical Associations and Outcome. Plasma Exchange/Sandoglobulin Guillain-Barre Syndrome Trial Group. Ann Neurol (1998) 44(5):780-8. doi: 10.1002/ ana. 410440512

4. Meyer zu Horste G, Hartung HP, Kieseier BC. From Bench to BedsideExperimental Rationale for Immune-Specific Therapies in the Inflamed Peripheral Nerve. Nat Clin Pract Neurol (2007) 3(4):198-211. doi: 10.1038/ ncpneuro0452

5. Kieseier BC, Kiefer R, Gold R, Hemmer B, Willison HJ, Hartung HP. Advances in Understanding and Treatment of Immune-Mediated Disorders of the Peripheral Nervous System. Muscle Nerve (2004) 30(2):131-56. doi: $10.1002 /$ mus.20076

6. Haber P, DeStefano F, Angulo FJ, Iskander J, Shadomy SV, Weintraub E, et al. Guillain-Barre Syndrome Following Influenza Vaccination. JAMA (2004) 292 (20):2478-81. doi: 10.1001/jama.292.20.2478

7. Jander S, Stoll G. Interleukin-18 Is Induced in Acute Inflammatory Demyelinating Polyneuropathy. J Neuroimmunol (2001) 114(1-2):253-8. doi: 10.1016/S0165-5728(00)00460-4

8. Zhang HL, Zheng XY, Zhu J. Th1/Th2/Th17/Treg Cytokines in GuillainBarre Syndrome and Experimental Autoimmune Neuritis. Cytokine Growth Factor Rev (2013) 24(5):443-53. doi: 10.1016/j.cytogfr.2013.05.005

9. Koller H, Kieseier BC, Jander S, Hartung HP. Chronic Inflammatory Demyelinating Polyneuropathy. N Engl J Med (2005) 352(13):1343-56. doi: 10.1056/NEJMra041347

10. Yasukawa H, Sasaki A, Yoshimura A. Negative Regulation of Cytokine Signaling Pathways. Annu Rev Immunol (2000) 18:143-64. doi: 10.1146/ annurev.immunol.18.1.143

11. Yamana J, Yamamura M, Okamoto A, Aita T, Iwahashi M, Sunahori K, et al. Resistance to IL-10 Inhibition of Interferon Gamma Production and Expression of Suppressor of Cytokine Signaling 1 in CD4+ T Cells From Patients With Rheumatoid Arthritis. Arthritis Res Ther (2004) 6(6):R567-77. doi: 10.1186/ar1445

12. Suzuki A, Hanada T, Mitsuyama K, Yoshida T, Kamizono S, Hoshino T, et al. CIS3/SOCS3/SSI3 Plays a Negative Regulatory Role in STAT3 Activation and Intestinal Inflammation. J Exp Med (2001) 193(4):471-81. doi: 10.1084/ jem.193.4.471

13. Seki $\mathrm{Y}$, Inoue $\mathrm{H}$, Nagata $\mathrm{N}$, Hayashi K, Fukuyama $\mathrm{S}$, Matsumoto K, et al. SOCS-3 Regulates Onset and Maintenance of $\mathrm{T}(\mathrm{H}) 2$-Mediated Allergic Responses. Nat Med (2003) 9(8):1047-54. doi: 10.1038/nm896

14. Toghi M, Taheri M, Arsang-Jang S, Ohadi M, Mirfakhraie R, Mazdeh M, et al. SOCS Gene Family Expression Profile in the Blood of Multiple Sclerosis Patients. J Neurol Sci (2017) 375:481-5. doi: 10.1016/j.jns.2017.02.015

\section{AUTHOR CONTRIBUTIONS}

MT and SG-F wrote the draft and revised it. SA-J analyzed the data. SS, ME, and PS performed the experiment. All authors contributed to the article and approved the submitted version.

\section{FUNDING}

The current study was supported by a grant from Shahid Beheshti University of Medical Sciences.

15. Keshavarzi A, Eftekharian MM, Komaki A, Omrani MD, Oskooei VK, Taheri M, et al. Sexual Dimorphism in Up-Regulation of Suppressors of Cytokine Signaling Genes in Patients With Bipolar Disorder. BMC Psychiatry (2019) 19 (1):402. doi: 10.1186/s12888-019-2396-9

16. Li P, Wang S, Zhang R, Pei J, Chen L, Cao Y, et al. Identification of CSF Biomarkers by Proteomicsin Guillain-Barré Syndrome. Exp Ther Med (2018) 15(6):5177-82. doi: 10.3892/etm.2018.6117

17. Van den Bergh PY, Hadden RD, Bouche P, Cornblath DR, Hahn A, Illa I, et al. European Federation of Neurological Societies/Peripheral Nerve Society Guideline on Management of Chronic Inflammatory Demyelinating Polyradiculoneuropathy: Report of a Joint Task Force of the European Federation of Neurological Societies and the Peripheral Nerve Society First Revision. Eur J Neurol (2010) 17(3):356-63. doi: 10.1111/j.15298027.2010.00245.x

18. Leonhard SE, Mandarakas MR, Gondim FA, Bateman K, Ferreira ML, Cornblath DR, et al. Diagnosis and Management of Guillain-Barré Syndrome in Ten Steps. Nat Rev Neurol (2019) 15(11):671-83. doi: 10.1038/ s41582-019-0250-9

19. Rajabally YA, Durand MC, Mitchell J, Orlikowski D, Nicolas G. Electrophysiological Diagnosis of Guillain-Barré Syndrome Subtype: Could a Single Study Suffice? J Neurol Neurosurgery Psychiatry (2015) 86(1):115-9. doi: 10.1136/jnnp-2014-307815

20. Ali ZPM, Taheri M, Sangsefidi S, Arsang-Jang S, Mazdeh M, Zamani A, et al. Evaluation of Expression of STAT Genes in Immune-Mediated Polyneuropathies. J Mol Neurosci (2020) 8:1-8. doi: 10.1007/s12031-02001494-y

21. Mahdi-Rogers M, Rajabally YA. Overview of the Pathogenesis and Treatment of Chronic Inflammatory Demyelinating Polyneuropathy With Intravenous Immunoglobulins. Biologics: Targets Ther (2010) 4:45-9. doi: 10.2147/ BTT.S4881

22. Lehmann HC, Kohne A, Meyer zu Horste G, Dehmel T, Kiehl O, Hartung HP, et al. Role of Nitric Oxide as Mediator of Nerve Injury in Inflammatory Neuropathies. J Neuropathol Exp Neurol (2007) 66(4):305-12. doi: 10.1097/ nen.0b013e3180408daa

23. Gisselbrecht S. The CIS/SOCS Proteins: A Family of Cytokine-Inducible Regulators of Signaling. Eur Cytokine Network (1999) 10(4):463-70.

24. Hu X, Chen J, Wang L, Ivashkiv LB. Crosstalk Among Jak-STAT, Toll-Like Receptor, and ITAM-Dependent Pathways in Macrophage Activation. J Leukocyte Biol (2007) 82(2):237-43. doi: 10.1189/jlb.1206763

25. Trengove MC, Ward AC. SOCS Proteins in Development and Disease. Am J Clin Exp Immunol (2013) 2(1):1-29.

26. Egan PJ, Lawlor KE, Alexander WS, Wicks IP. Suppressor of Cytokine Signaling-1 Regulates Acute Inflammatory Arthritis and T Cell Activation $J$ Clin Invest (2003) 111(6):915-24. doi: 10.1172/JCI16156

27. Zhou D, Chen L, Yang K, Jiang H, Xu W, Luan J. SOCS Molecules: The Growing Players in Macrophage Polarization and Function. Oncotarget (2017) 8(36):60710-22. doi: 10.18632/oncotarget.19940

28. Basrai HS, Christie KJ, Turbic A, Bye N, Turnley AM. Suppressor of Cytokine Signaling-2 (SOCS2) Regulates the Microglial Response and Improves Functional Outcome After Traumatic Brain Injury in Mice. PloS One (2016) 11(4):e0153418. doi: 10.1371/journal.pone.0153418 
29. Leung KC, Doyle N, Ballesteros M, Sjogren K, Watts CK, Low TH, et al. Estrogen Inhibits GH Signaling by Suppressing GH-Induced JAK2 Phosphorylation, an Effect Mediated by SOCS-2. Proc Natl Acad Sci USA (2003) 100(3):1016-21. doi: 10.1073/pnas.0337600100

30. Takeda K, Clausen BE, Kaisho T, Tsujimura T, Terada N, Forster I, et alEnhanced Th1 Activity and Development of Chronic Enterocolitis in Mice Devoid of Stat3 in Macrophages and Neutrophils. Immunity (1999) 10 (1):39-49. doi: 10.1016/S1074-7613(00)80005-9

31. Wang Y, Sun S, Zhu J, Cui L, Zhang H-L. Biomarkers of Guillain-Barre Syndrome: Some Recent Progress, More Still to be Explored. Mediators Inflamm (2015) 2015. doi: 10.1155/2015/564098

32. Piessevaux J, Lavens D, Montoye T, Wauman J, Catteeuw D, Vandekerckhove J, et al. Functional Cross-Modulation Between SOCS Proteins can Stimulate Cytokine Signaling. J Biol Chem (2006) 281(44):32953-66. doi: 10.1074/ jbc.M600776200

33. Tannahill GM, Elliott J, Barry AC, Hibbert L, Cacalano NA, Johnston JA. SOCS2 can Enhance Interleukin-2 (IL-2) and IL-3 Signaling by Accelerating
SOCS3 Degradation. Mol Cell Biol (2005) 25(20):9115-26. doi: 10.1128/ MCB.25.20.9115-9126.2005

34. Ghafouri-Fard S, Oskooei VK, Azari I, Taheri M. Suppressor of Cytokine Signaling (SOCS) Genes Are Downregulated in Breast Cancer. World J Surg Oncol (2018) 16(1):226. doi: 10.1186/s12957-018-1529-9

Conflict of Interest: The authors declare that the research was conducted in the absence of any commercial or financial relationships that could be construed as a potential conflict of interest.

Copyright (C) 2021 Taheri, Sangseifid, Shahani, Eftekharian, Arsang-Jang and Ghafouri-Fard. This is an open-access article distributed under the terms of the Creative Commons Attribution License (CC BY). The use, distribution or reproduction in other forums is permitted, provided the original author(s) and the copyright owner(s) are credited and that the original publication in this journal is cited, in accordance with accepted academic practice. No use, distribution or reproduction is permitted which does not comply with these terms. 